\title{
Automatic Wireless Ambient Air and Weather Condition Monitoring System for Outdoor Environment Monitoring Applications
}

\author{
C. Bambang Dwi Kuncoro, ${ }^{1,2}$ Win-Jet Luo, ${ }^{1}$ M. Rezki Selamet, ${ }^{2}$ \\ Sri Mulyati N, ${ }^{2}$ Kurniawan Andi $S,{ }^{2}$ and Yean-Der Kuan ${ }^{3 *}$ \\ ${ }^{1}$ Graduate Institute of Precision Manufacturing, National Chin-Yi University of Technology, \\ No. 57, Sec. 2, Zhongshan Rd., Taiping Dist., Taichung City 41170, Taiwan \\ ${ }^{2}$ Electrical and Instrumentation Laboratory, Politeknik Negeri Bandung, \\ Jl. Gegerkalong Hilir, Ds. Ciwaruga, Bandung 40012, Jawa Barat, Indonesia \\ ${ }^{3}$ Department of Refrigeration, Air Conditioning and Energy Engineering, National Chin-Yi University of \\ Technology, No. 57, Sec. 2, Zhongshan Rd., Taiping Dist., Taichung City 41170, Taiwan
}

(Received February 6, 2019; accepted November 21, 2019)

Keywords: wireless, sensor array, environment, air quality, monitoring

Real-time, reliable, accurate, and comprehensive ambient air condition information over time is required in many fields and applications, including medical, scientific, and industrial applications as well as daily life human activities. Such information can be used to enhance the quality and living conditions of humans. Moreover, reliable, accurate, and comprehensive environment condition information helps in solving environmental problems. In this paper, we present a data logging and monitoring system to record air ambient conditions, air quality, and daily weather conditions using a low-cost, fully automated, wireless, real-time, reliable, continuous-logging, portable, and user-friendly device. The proposed device consists of two main parts: a monitoring device and a monitoring terminal. The monitoring terminal is based on an embedded system and a smart electronic sensor array to sense some environmental parameters such as ambient temperature, ambient relative humidity, ambient air pressure, carbon monoxide level, carbon dioxide level, gas methane level, dust particulate level, wind speed, wind direction, and rainfall. All parameter data are recorded in a data logger and displayed on a liquid crystal display (LCD). Environmental parameter data are sent to the monitoring terminal by a Bluetooth module. The parameter data is visualized on a user-friendly graphical user interface (GUI) application that can work on either a notebook or a smartphone platform. The test and validation show that the developed system successfully accomplished environmental condition logging and monitoring wirelessly. The environmental conditions were recorded and monitored by the developed system over a long period of time and in real time with a data transmission rate delay of $2.8 \mathrm{~s}$ from the monitoring device to the monitoring terminal.

*Corresponding author: e-mail: ydkuan@ncut.edu.tw https://doi.org/10.18494/SAM.2020.2604 


\section{Introduction}

Air condition, air quality, and weather/climate play an important role in human life as important factors that affect the quality of life. Air quality is indicated by pollutant quantities and types. Several health hazards such as organic dust toxic syndrome, asthma pneumonitis, legionnaire's central nervous system symptoms, sinusitis, nasal irritation, and allergy are caused by air pollutants. ${ }^{(1)}$ Many different areas of human life (e.g., in industry, building design, laboratories, economics and business, forestry, agriculture, irrigation and hydrology, and public health) are highly dependent on temperature and humidity factors. ${ }^{(2-6)}$

The air condition, air quality, and weather/climate on Earth's surface continuously vary. Fluctuations in temperature, relative humidity, wind speed, and atmospheric brightness occur. ${ }^{(7)}$ Many factors are involved in these conditions. These factors include the sun's position relative to Earth, the amount of solar radiation reaching Earth's surface, Earth's rotation, the latitude position of somewhere on Earth's surface, the geographical region (beach, mountains), as well as atmospheric condition. To describe the air conditions and quality, certain key air parameters must be known and quantified. Some of those important parameters are temperature, relative humidity, atmospheric pressure, wind speed, wind direction, cloud cover, precipitation, CO level, $\mathrm{CO}_{2}$ level, and dust particulate level.

Remote monitoring systems closely related to the outstanding advances in electronics and instrumentation technologies have emerged. Therefore, the rapid evolution of air condition and quality data logging systems over the last two decades has resulted in numerous data acquisition systems developed in the electronics field. One of the earliest examples, telemetry experiments using satellite-relay systems for remote hydrologic data collection in the $70 \mathrm{~s}$, should be remembered. ${ }^{(8)}$ Since then, real-time monitoring systems with new devices and tools have appeared. More powerful low-cost data collection resources are now available. Hence, remote environmental monitoring systems are gaining market share in diversified areas such as in industry, security, education, and even in health-care applications. More and better systems with higher transmission rates can be developed using today's technological advances. This consequently increases system complexity and budget.

Some research studies on environmental monitoring applications were conducted over recent years. Singh and Sarma developed a low-cost data acquisition system based on a microcontroller for temperature and humidity monitoring in real time. ${ }^{(3)}$ The data signal waveform can be displayed on a computer in real time and can also be saved into a computer hard disk for future use and analysis. Nhivekar and Mudholker introduced environmental parameter data logging and remote monitoring as well as temperature and humidity information sent to a user's mobile phone through the short message service (SMS). ${ }^{(4)}$ Further analysis or printing the measurements can be performed using logged data that are transmitted to a personal computer (PC) having a graphical user interface (GUI) program. Noordin et al. developed a weather monitoring system to monitor the atmospheric temperature, pressure, and relative humidity. ${ }^{(5)}$ The data can be transferred to a PC through a USB link and displayed on a GUI. The developed device is small, accurate, reliable, cheap, and portable with a large 
memory capacity and reconfigured data sampling parameters. In Ref. 9, the authors presented an environment monitoring system based on a wireless sensor network (WSN) for smart city application. It is characterized by low power, low cost, small size, and rapid connection to a network topology. The monitored environments include the dust particulate level, acoustic level, environmental temperature, and relative humidity. The sensing data are stored in a remote database allowing it to be visualized in real time through a web server. The main goal is the optimization of the environmental parameter sensing process and low-rate data transmission from a sensor to a web server. Yi et al. introduced an air pollution monitoring modular design for the urban environment. ${ }^{(10)}$ The developed system has multiple sensing capabilities and a configurable and adaptable low-concentration air pollution sensing capability with high energy efficiency, multiple WSN compatibility, and good data accuracy. The environmental parameters include the $\mathrm{CO}$ and $\mathrm{NO}_{2}$ concentrations, temperature, atmospheric pressure, and relative humidity. In Ref. 11, the authors presented a low-cost, robust air quality station for realtime $\mathrm{CO}, \mathrm{CO}_{2}, \mathrm{NO}_{2}, \mathrm{O}_{3}, \mathrm{VOC}, \mathrm{PM}_{2.5}$, and $\mathrm{PM}_{10}$ monitoring. Xin et al. proposed a wireless environmental monitoring system to enhance the real-time environmental parameter collection reliability and communication capacity. ${ }^{(12)}$ They were concerned with power consumption reduction for reliable environmental, temperature, and illumination information monitoring. Tahir et al. presented a laboratory instrument system for temperature, wind speed, and wind direction monitoring. ${ }^{(13)}$ The system uses a microcomputer and visual basic language for the processing and monitoring of environmental weather data acquisition. The authors of Ref. 14 proposed an Internet of Things (IoT)-based air quality monitoring system for air pollution. This system can monitor, update, and display air quality, temperature, and humidity online because it is a real-time web-based cloud application. Moreover, when the air quality is poor, the system sends an email alert notification to the user. Prasad et al. presented an effective solution for pollution monitoring using WSN in real time. ${ }^{(15)}$ The system senses the concentration of gases such as $\mathrm{CO}_{2}, \mathrm{NO}_{2}, \mathrm{CO}$, and $\mathrm{O}_{2}$, and pollution data can be viewed live using a web interface from anywhere as long as the Internet is available. In Ref. 16, the authors presented an environmental air pollution monitoring system for monitoring $\mathrm{CO}, \mathrm{NO}_{2}$, and $\mathrm{SO}_{2}$ over GSM and GPS modules. The data can be shown in a PC application server with Internet connectivity, and it also interfaced to Google Maps to display the hardware unit location. However, in the research works above, various applications require common tasks with simple and cheap systems to perform control or monitor action. In some cases, there is a necessary command to collect a very small amount of data, and a few characters in a simple text message can be sent to perform a specific action.

This research work's main contribution is the development of a low-cost, fully automated, wireless, real-time, reliable, continuous-logging, portable, and user-friendly data logging and monitoring system to record air ambient conditions, air quality, and daily weather conditions. The system includes a GUI application that allows showing all environmental parameters on either a notebook or a smartphone over wireless communication based on Bluetooth technology. The proposed device presented in this paper was developed on the basis of previous research as described in Sect. 2.1. 


\section{Materials and Methods}

\subsection{Previous work overview}

In a previous work, ${ }^{(17)}$ a wireless ambient air condition monitoring system was deployed for environmental monitoring applications as shown in Fig. 1. The system consists of two main parts: a monitoring device and a monitoring terminal. The monitoring device consists of smart electronic sensors (temperature, relative humidity, and atmospheric sensors), a microcontroller, a liquid crystal display (LCD) monitor, a data logger module, a Bluetooth transmitter, and a power supply. The environmental parameters are visualized on a monitoring terminal GUI. This system was developed using the virtual instrumentation software tool and works in a notebook/PC platform.

Experimental results have shown that environmental monitoring can be performed easily, accurately, continuously, remotely, effectively, and in real time using the developed system. The device was able to monitor the ambient air condition with accuracy rates of $0.5{ }^{\circ} \mathrm{C}, 3.5 \%$, and $700-900 \mathrm{hPa} \pm 0.12 \mathrm{hPa}$ for temperature, humidity and atmospheric pressure, respectively. It has a data transmission rate delay of around $5.8 \mathrm{~s}$.

\subsection{System design}

As mentioned earlier, in this work, we developed a data logging monitoring system to record air ambient conditions, air quality, and daily weather conditions as described in the system architecture in Fig. 2.

The system architecture is composed of four main subsystems: environment, monitoring device, fixed monitoring terminal, and mobile monitoring terminal. This research work is based on a previous research and each subsystem function in Fig. 2 is described in Ref. 17.

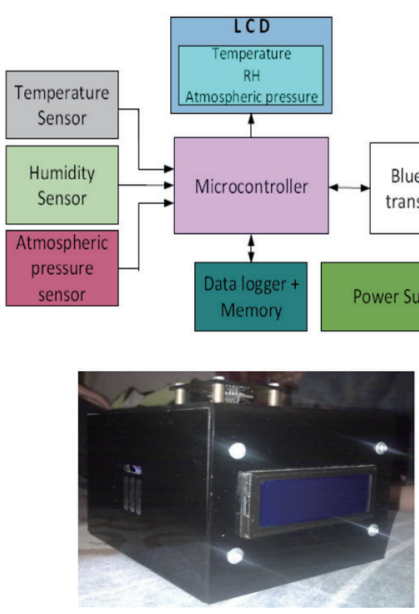

(a)

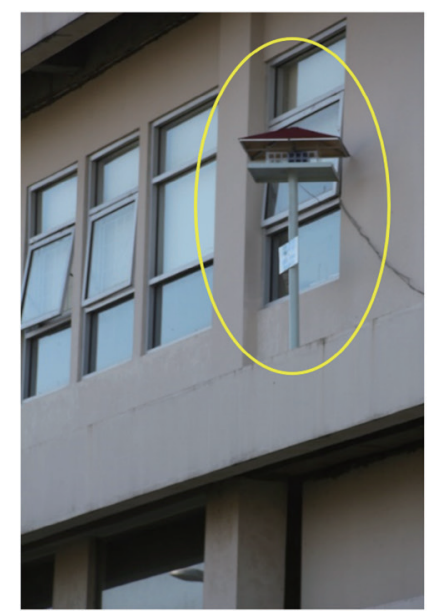

(b)

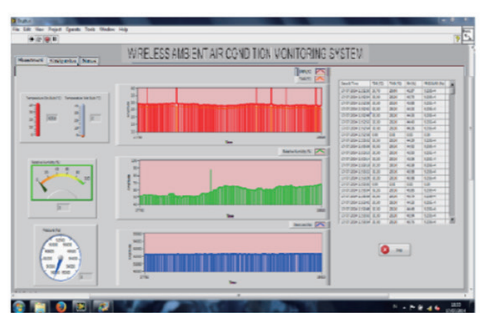

(c)

Fig. 1. (Color online) Wireless ambient air condition monitoring system: (a) monitoring device, (b) housing tower, and (c) fixed monitoring terminal GUI. ${ }^{(17)}$ 


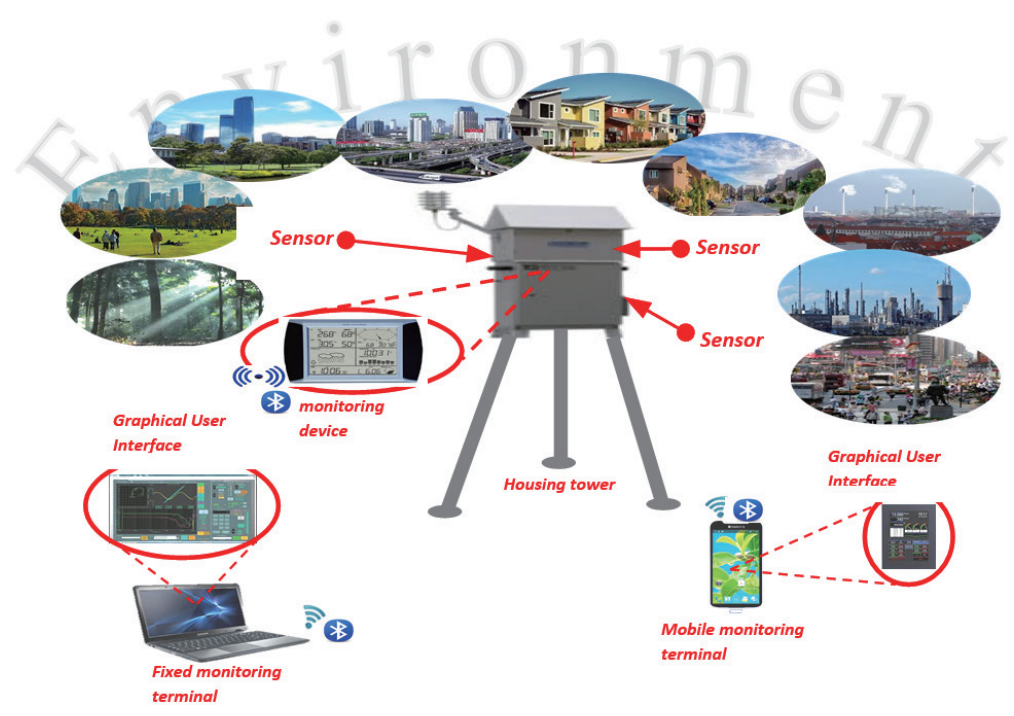

Fig. 2. (Color online) Proposed system architecture. ${ }^{(17)}$

Air quality and weather condition sensors are added to the previous developed system in this research work to improve the system capability to record and monitor daily ambient air quality and outdoor weather conditions. A user-friendly, easy-to-use GUI for both fixed monitoring terminal (laptop/PC) and mobile monitoring terminal platforms is developed to improve the proposed system mobility feature. Moreover, the monitoring device will be placed in a portable housing tower that permits switching over conveniently to different monitoring areas.

\subsection{Monitoring device}

The main monitoring device component is a microcontroller. It processes and analyzes environmental parameters collected using an electronic sensor array. The sensor array includes ambient air conditioning sensors (temperature, relative humidity, and atmospheric pressure), air quality sensors (carbon monoxide, carbon dioxide, methane, and dust particulates), and weather condition sensors (wind speed, rainfall, and wind direction). The environmental data processing results are displayed on an LCD or saved into data logger memory in Microsoft Excel ${ }^{\circledR}$ file format for future analysis. The data is also sent to a monitoring terminal over a Bluetooth transmitter to be visualized on a GUI or saved into a monitoring terminal memory/hard disk in virtual instrumentation or Microsoft Excel ${ }^{\circledR}$ file format. The power supply provides power to every monitoring device component. The proposed monitoring device block diagram is shown in Fig. 3.

A compact design is also pursued to achieve convenience, portability, and safety. All monitoring device components are placed into a compact, simple casing design as illustrated in Fig. 4(a). The monitoring device is placed on top of a portable housing tower (housing part). The housing was designed by considering that the sensors of ambient air condition and air quality can still easily sense environmental parameters. The portable housing tower design is shown in Fig. 4(b). 


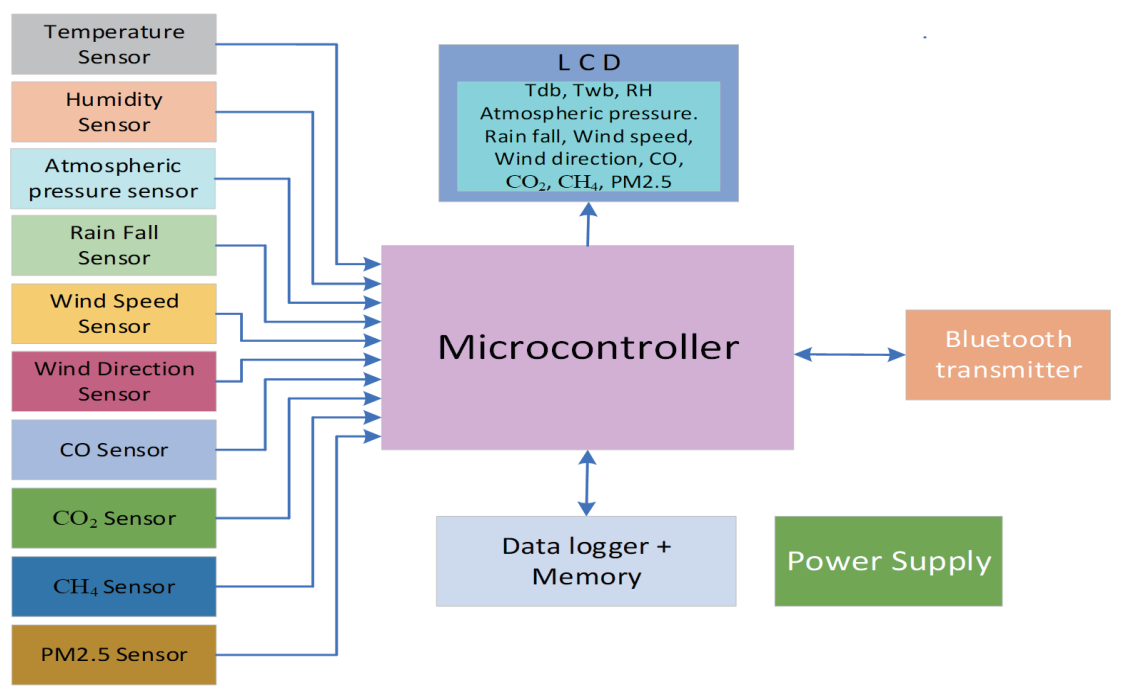

Fig. 3. (Color online) Proposed monitoring device block diagram.

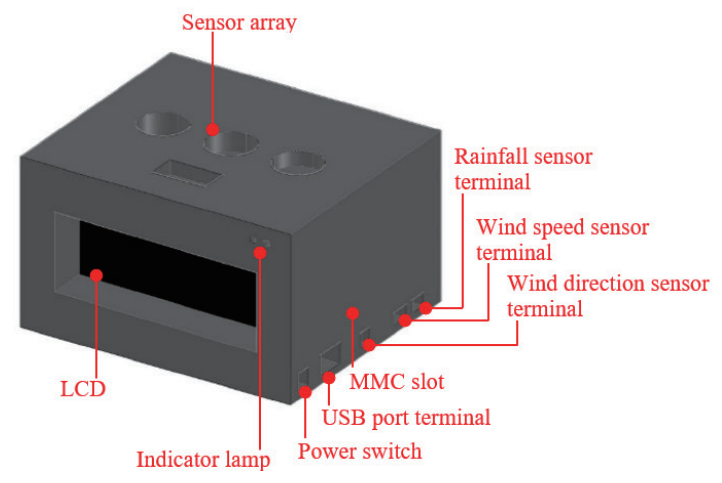

(a)

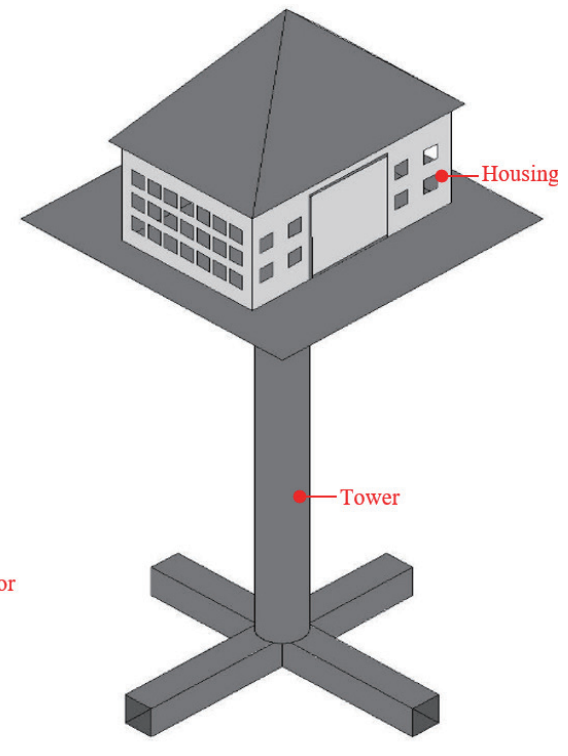

(b)

Fig. 4. (Color online) Conceptual designs: (a) casing design and (b) portable housing tower design.

\subsection{Monitoring algorithm}

An algorithm that runs a microcontroller module is developed to perform monitoring device functions. The algorithm enables all environmental parameters sensed by the sensor array to be collected and processed by the microcontroller. The processing result is shown on an LCD or saved in memory. All environmental information is sent to the monitoring terminal over radio communication. The algorithm is described as follows: 
1. Initialize Bluetooth connection.

Establish serial communication between monitoring device and monitoring terminal.

2. Collect the temperature, relative humidity, atmospheric pressure, carbon monoxide, carbon dioxide, methane, dust particulate, wind speed, rainfall, and wind direction from the array sensor.

3. Process and analyze all data to provide environmental air condition, air quality, and weather information.

4. Display the temperature (Tdb, Twb), relative humidity, atmospheric pressure, carbon monoxide, carbon dioxide, methane, dust particulate, wind speed, rainfall, wind direction information on the LCD.

5. Store the temperature (Tdb, Twb), relative humidity, atmospheric pressure, carbon monoxide, carbon dioxide, methane, dust particulate, wind speed, rainfall, and wind direction information into the memory.

6. Finally, send the temperature (Tdb, Twb), relative humidity, atmospheric pressure, carbon monoxide, carbon dioxide, methane, dust particulate, wind speed, rainfall, and wind direction information over radio communication.

\subsection{GUI development}

A GUI is developed for the monitoring terminal. The user interface is based on the PC and mobile device platforms. The GUI enables all environmental parameters to be visualized as either numeric or graphical information. It includes alarm/notification for the user if the data/information is greater than a set threshold value. Figure 5 shows the flowchart diagram for GUI development.

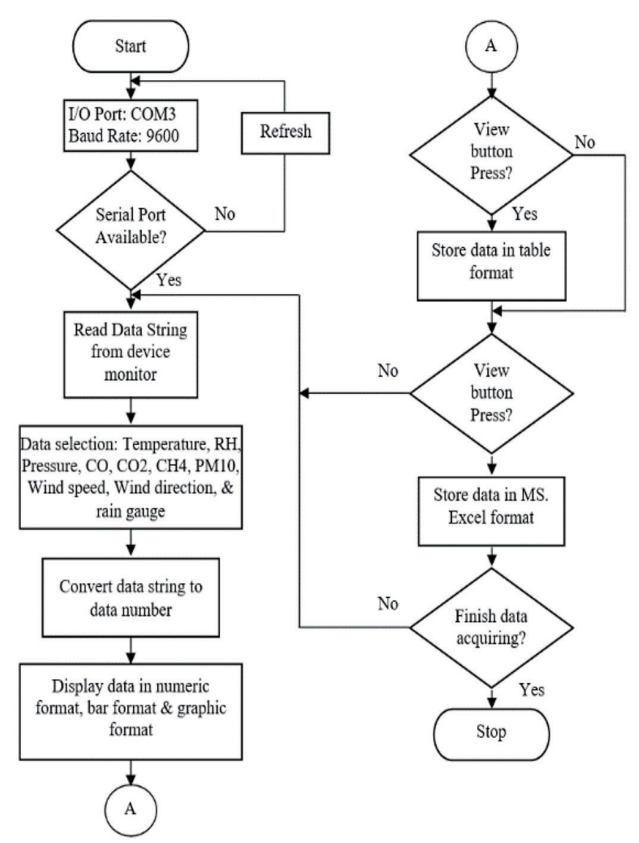

(a)

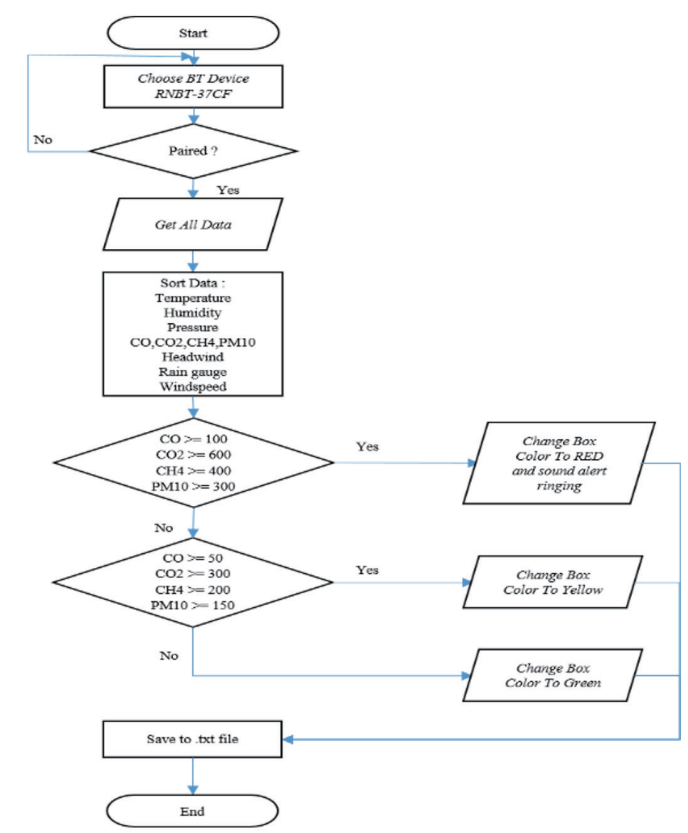

(b)

Fig. 5. Flowchart diagram for monitoring terminal: (a) fixed monitoring and (b) mobile monitoring. 


\section{System Implementation}

\subsection{Monitoring device}

The monitoring device electronic circuit is shown in Fig. 6(a). It includes a Bluesmirf Gold Mate module, a data logger shield with a real-time clock (RTC) module, and an LCD $20 \times 4$ directly connected to an Arduino Mega as the main component. The SHT11 and BMP180 modules are connected to the Arduino Mega I2C interface as a temperature-relative humidity sensor and an atmospheric sensor, respectively. The MQ-7 (a carbon monoxide sensor), MQ-4 (a methane sensor), MG811 (a carbon dioxide sensor), and wind direction (a wind direction sensor) modules were connected to the Arduino Mega analog input terminals. On the other hand, the DSM500A (a dust particulate sensor), wind speed (a wind speed sensor), and rainfall (a rainfall sensor) modules were connected to the Arduino Mega digital input terminals. A wall power supply with a nominal output voltage of $9 \mathrm{~V}$ at $1 \mathrm{~A}$ is used as the power source.

All monitoring device components are placed in a casing as shown in Fig. 6(b). The component layout was arranged to fit a small casing. The casing had dimensions of $15 \times 12 \times 10 \mathrm{~cm}^{3}$ and was made using acrylic material. The monitoring device final integration is shown in Fig. 7. The monitoring device is put in the portable housing tower.

\subsection{Monitoring terminal GUI}

On the fixed monitoring terminal side, a GUI application was developed using the LabVIEW ${ }^{\text {TM }}$ software developed by National Instruments Corporation. This user interface provides a very flexible platform for data acquisition, data processing, instrument control, industrial automation, and other end-user applications. ${ }^{(18)}$ This is a dataflow- and graphics-based language and is appropriate for a man-machine interface design. ${ }^{(19)}$ The fixed monitoring terminal GUI was developed on the basis of the algorithm shown in Fig. 5(a). The programming structure is shown in Fig. 8. It includes a Visa interface to make serial

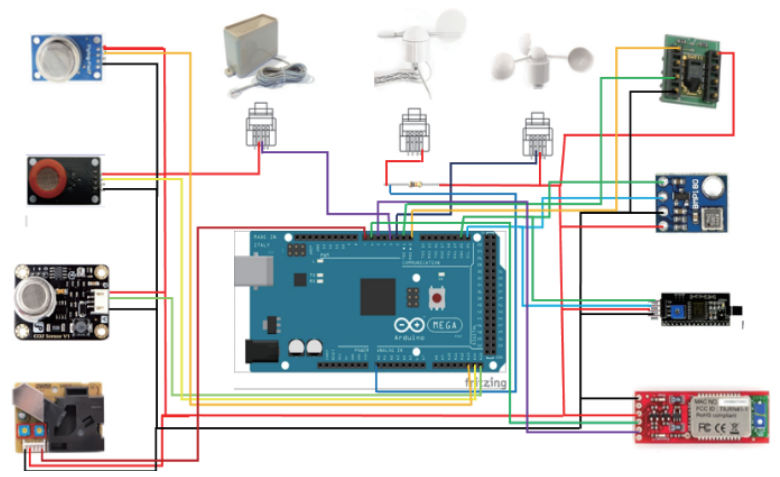

(a)

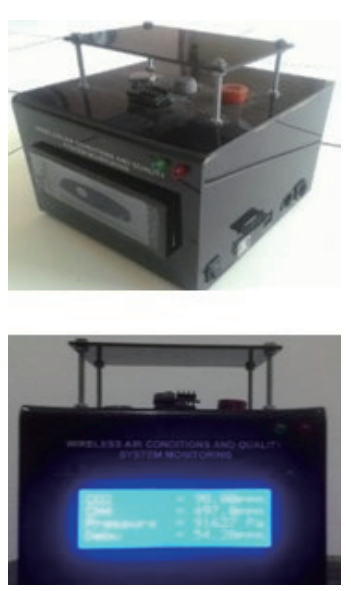

(b)

Fig. 6. (Color online) Implemented monitoring device: (a) circuit diagram and (b) final design. 


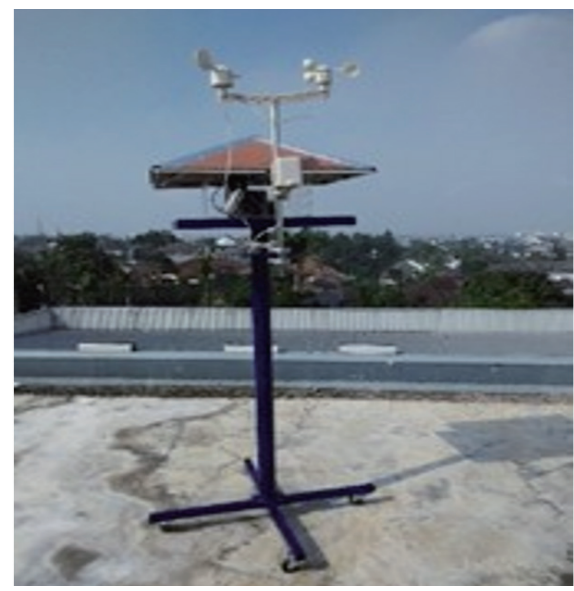

(a)

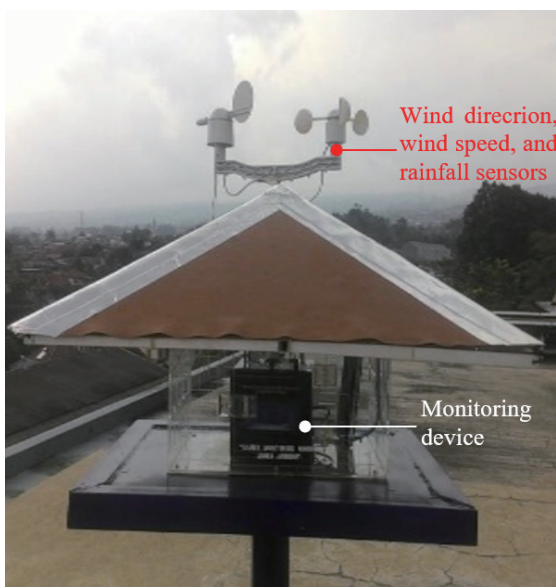

(b)

Fig. 7. (Color online) Monitoring device final integration: (a) portable housing tower and (b) monitoring device housing.

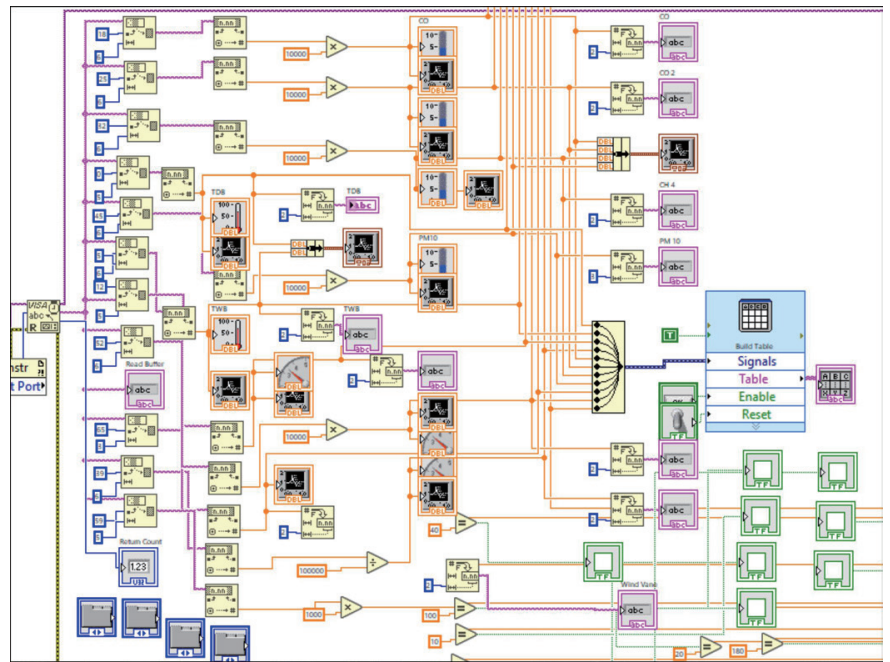

(a)

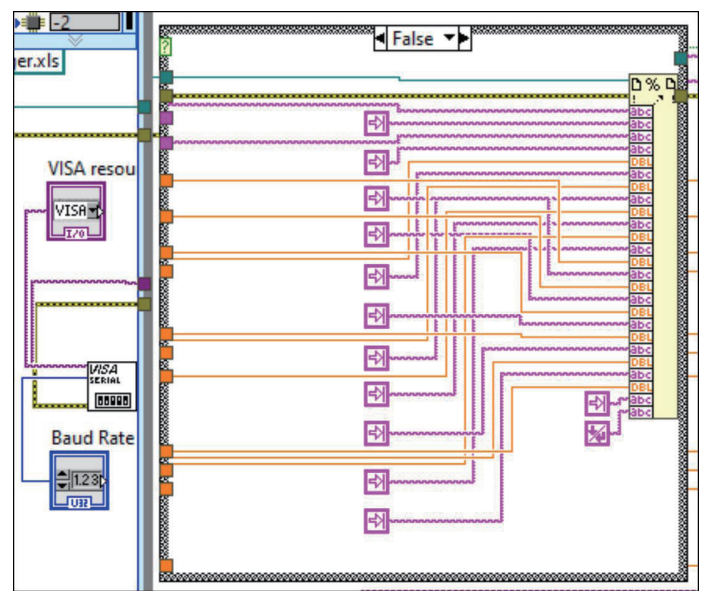

(b)

Fig. 8. (Color online) GUI block diagram for fixed monitoring terminal design: (a) main program and (b) Visa configure serial port.

communication connections with the Bluetooth module [Fig. 8(b)] and a main program [Fig. 8(a)] where the packet data from the Bluetooth module will be extracted in small data packets to present the appropriate environmental condition information.

The GUI implementation is shown in Fig. 9. All environmental condition data are visualized in either numeric or graphic format in different windows, reflecting real-time environmental conditions.

The GUI also provides a data logger to record a set of environmental parameters as well as monitoring time (date, time), air temperature ( $\mathrm{Tdb}$, Twb), air relative humidity, $\mathrm{CO}$ level, $\mathrm{CO}_{2}$ 


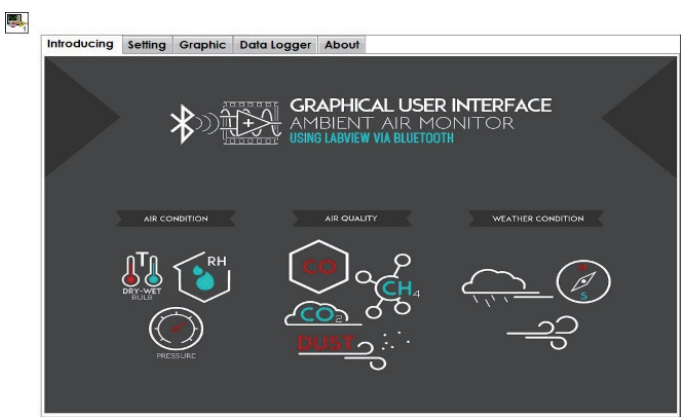

(a)

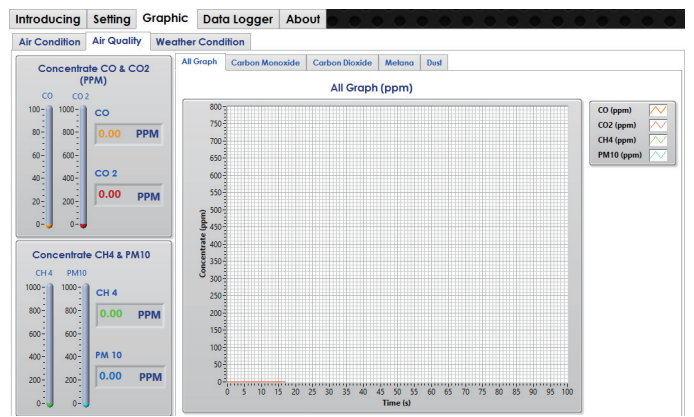

(c)

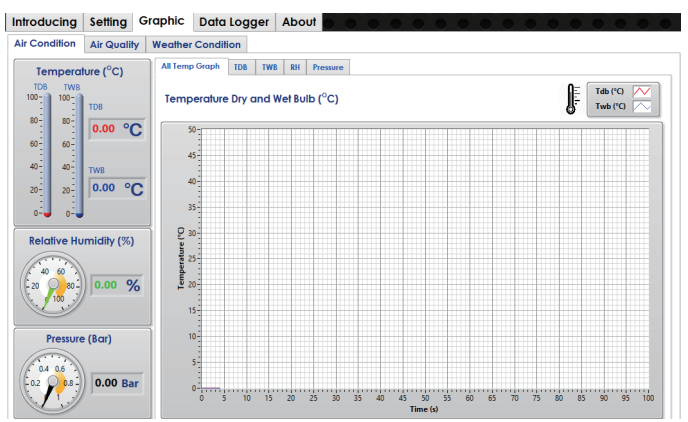

(b)

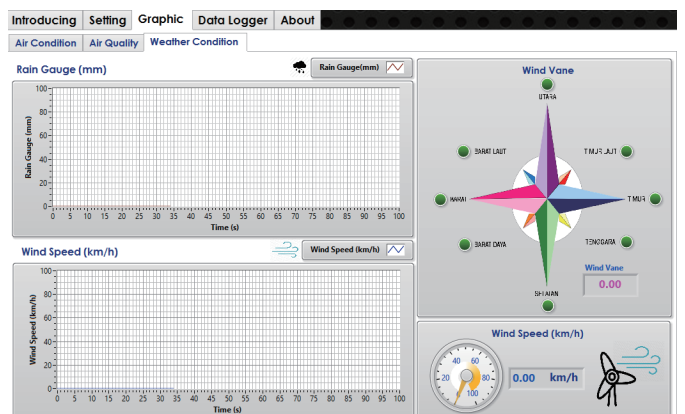

(d)

Fig. 9. (Color online) Implemented GUI for fixed monitoring terminal: (a) introduction section, (b) environmental air condition parameters, (c) environmental air quality parameters, and (d) weather condition parameters.

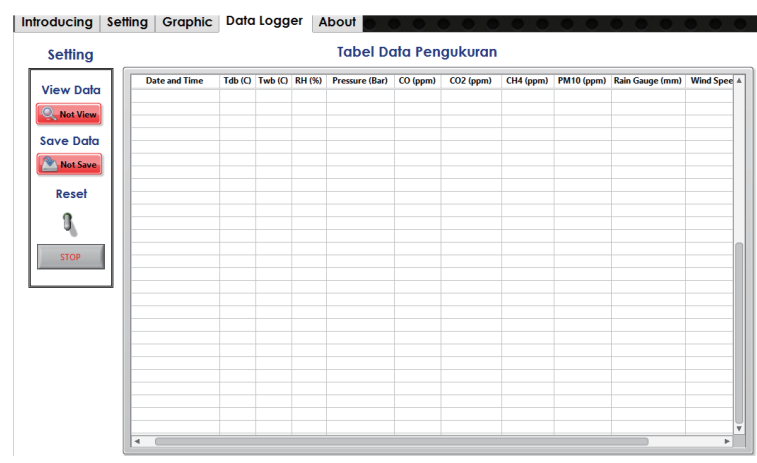

Fig. 10. (Color online) Data logger section for fixed monitoring terminal.

level, $\mathrm{CH}_{4}$ level, dust particulate level, rainfall level, wind speed, and wind direction in a table with the real-time numerical data. This database was realized using Microsoft Excel ${ }^{\circledR}$. A Microsoft Excel ${ }^{\circledR}$ worksheet is created and named "Air_Condition_Quality_Database". The GUI interacts with this database by writing data to and reading data from it. The data logger window is shown in Fig. 10.

The mobile terminal GUI was developed using the AppInventor application software developed by the Massachusetts Institute of Technology (MIT) Media Lab. ${ }^{(20)}$ It is an opensource web application originally provided by Google for Android. The mobile monitoring 
terminal GUI was developed on the basis of the diagram shown in Fig. 5(b). It is composed of a screen design and block functions as shown in Fig. 11.

The mobile monitoring terminal GUI implementation is shown in Fig. 12. This user interface runs in an Android smartphone. It is composed of four screens: opening screen, information screen, two environmental parameters monitoring screens, and environmental parameters information screen. In the information screen, the user obtains information regarding this application and how to use the application. The environmental parameters monitoring screen visualizes the environmental parameters in numeric and bar chart data. This screen also provides automatic alarm/notification if the monitored environmental parameter

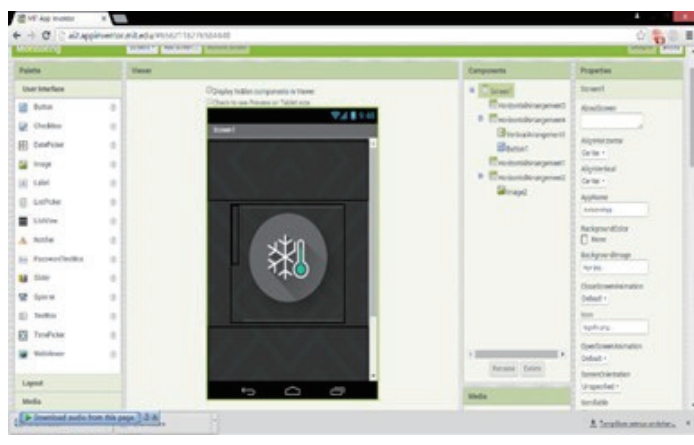

(a)

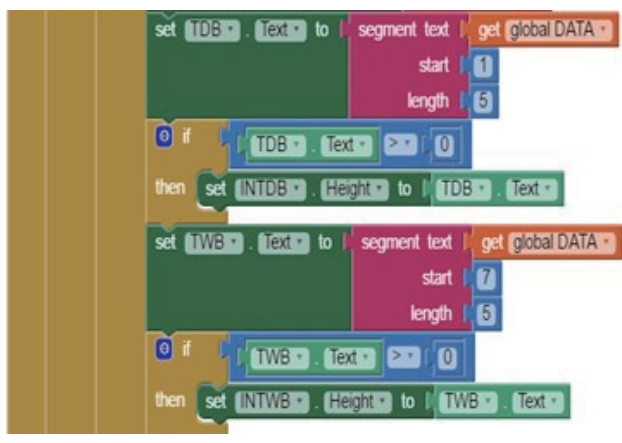

(b)

Fig. 11. (Color online) GUI block diagram for mobile monitoring terminal design: (a) screen design and (b) block functions.

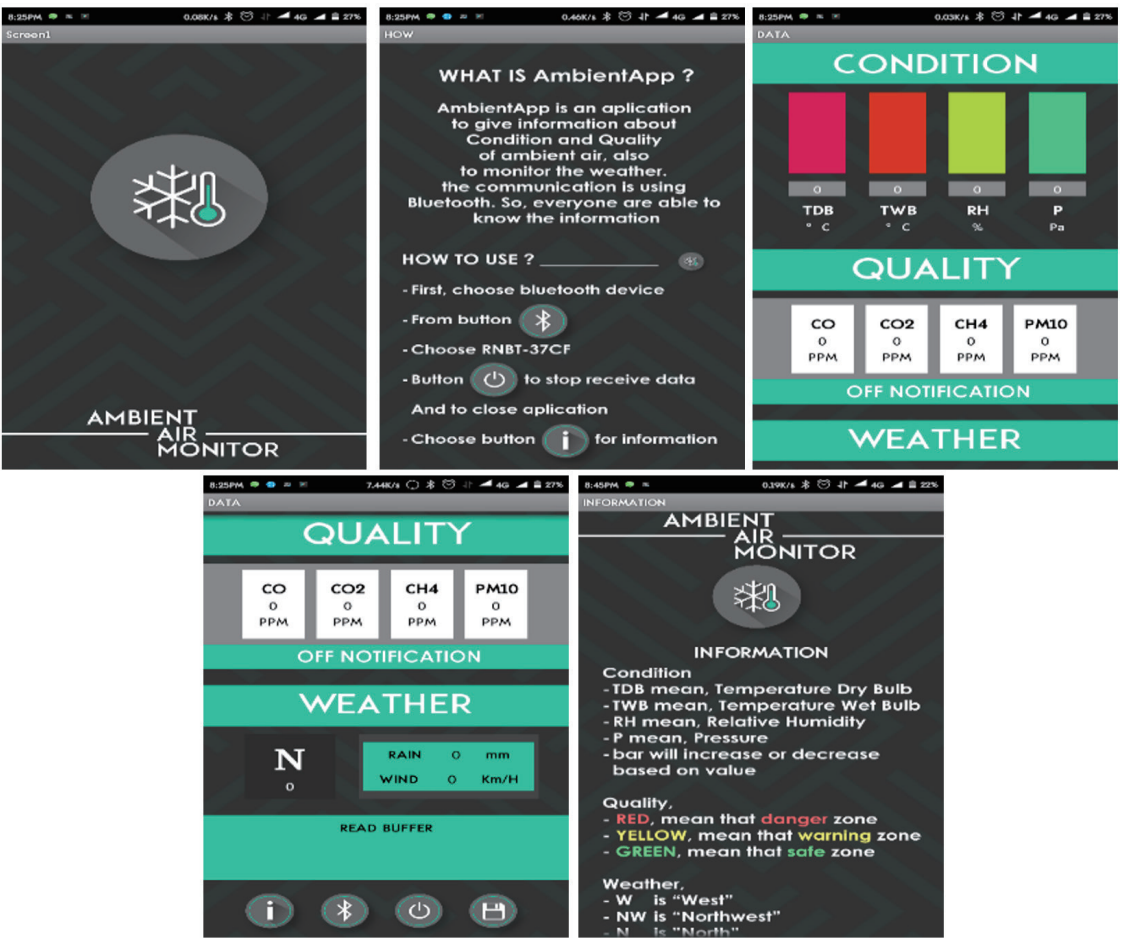

Fig. 12. (Color online) Implemented GUI for mobile monitoring terminal. 
rises above a set threshold value. All environmental condition information is shown in text mode. The txt file is created and named "LoggerMonitoring" to be saved in the smartphone memory as shown in Fig. 13.

\section{Experiment and Discussion}

\subsection{Experimental method}

An experiment was performed to test the monitoring device performance and validate the acquired environmental air condition, air quality, and weather condition data. The monitoring device was put on the fourth floor (rooftop) of a building. The environment condition was monitored by both a fixed monitoring terminal and a mobile monitoring terminal as shown in Fig. 14. The monitoring system was run for 15 days to monitor the environmental conditions around the building.

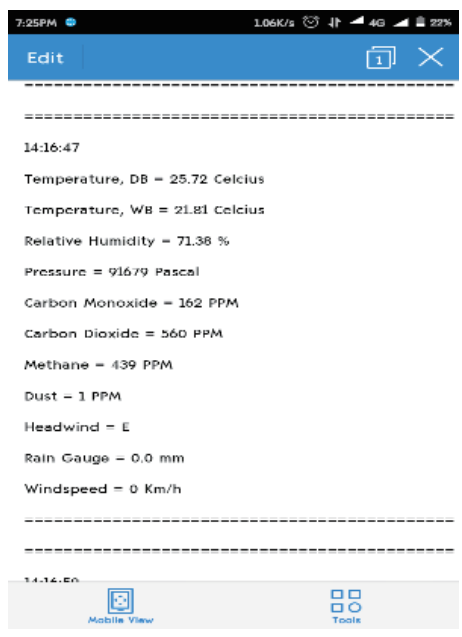

Fig. 13. (Color online) Mobile monitoring terminal data logger.

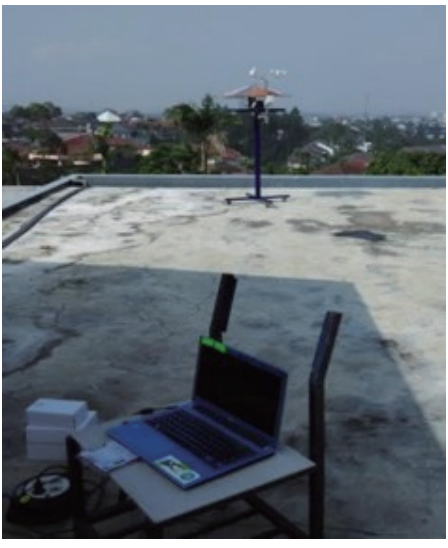

(a)

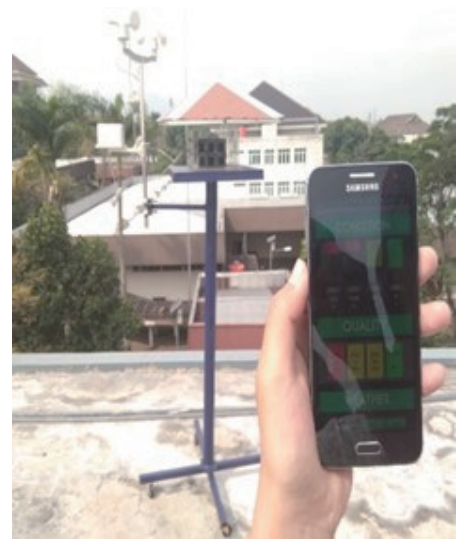

(b)

Fig. 14. (Color online) Experimental setup: (a) monitoring using fixed monitoring terminal and (b) monitoring using mobile monitoring terminal. 


\subsection{Results}

During the experiment, environment and weather conditions always changed as shown in Fig. 15. The days were sometimes sunny, sunny with clouds, cloudy, or rainy.

The environmental and weather conditions were recorded and visualized in a GUI as shown in Figs. 16 and 17(a). The environmental data trend is shown in the GUI graph with
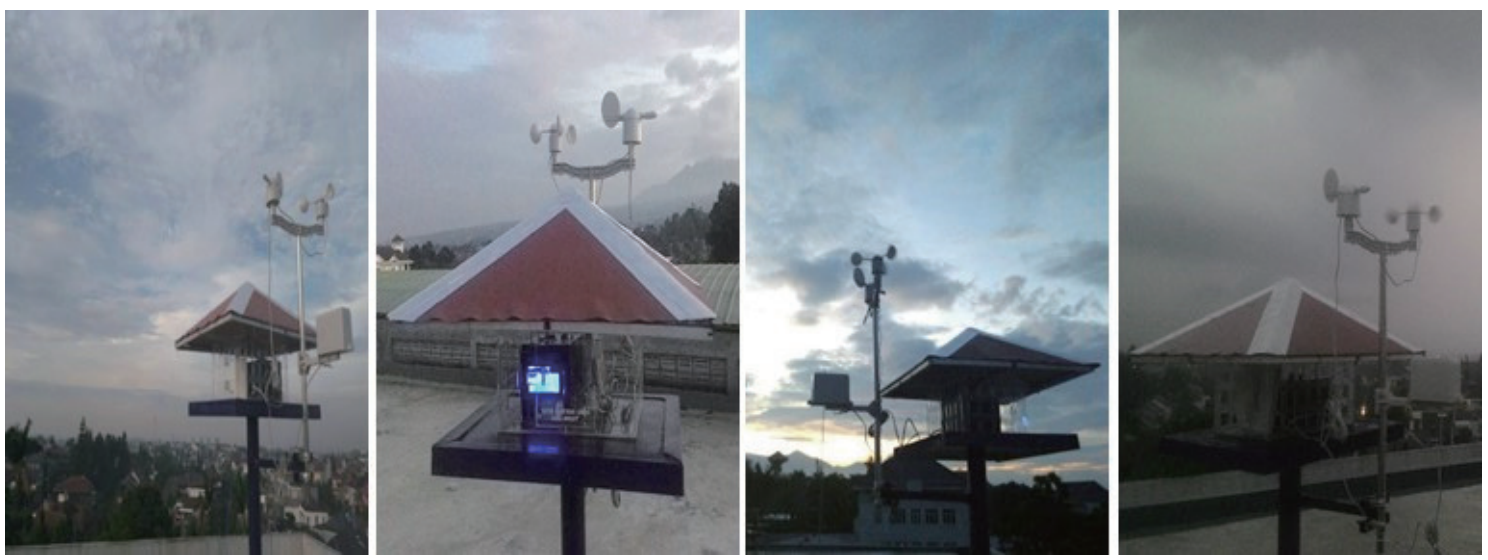

Fig. 15. (Color online) Monitoring device under different environmental and weather conditions.

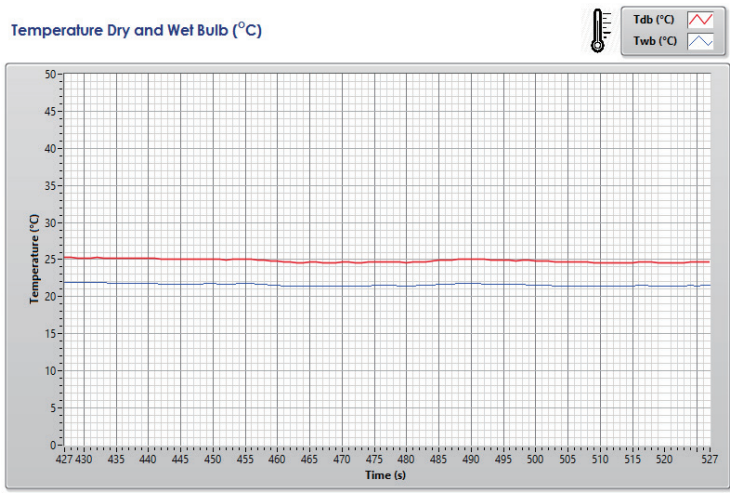

(a)

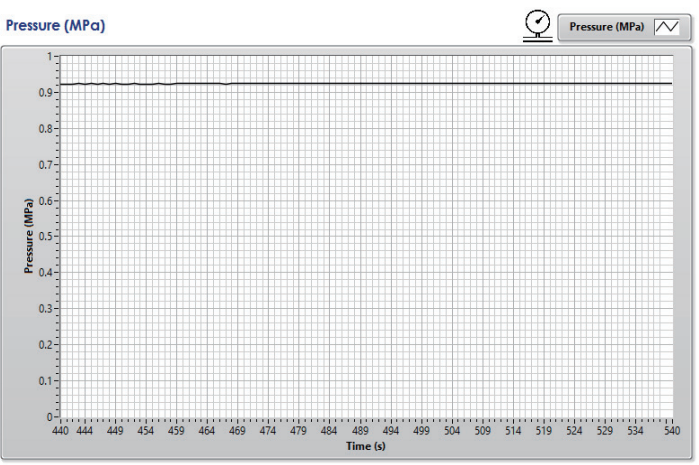

(c)

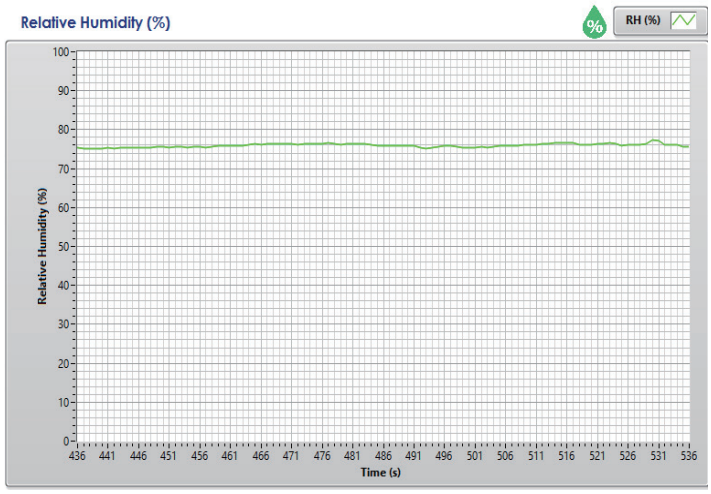

(b)

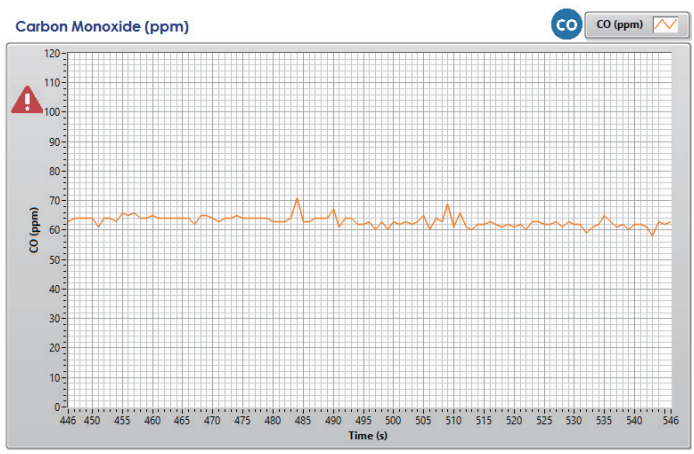

(d)

Fig. 16. (Color online) Screen shot experimental data on fixed monitoring terminal GUI: (a) wet and dry bulb temperature data trends and (b) humidity data trend. 


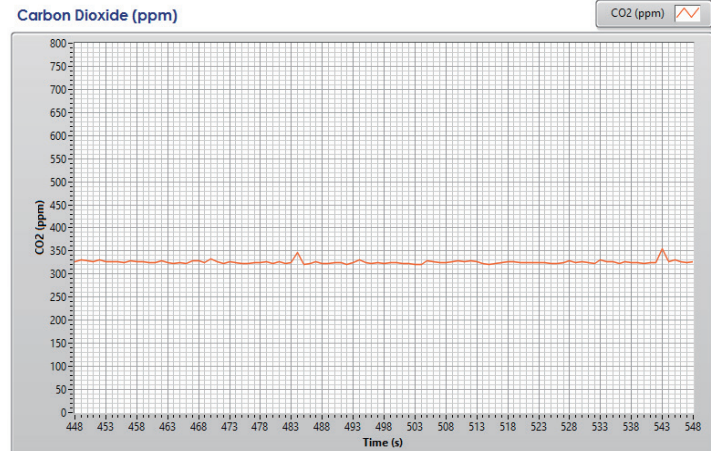

(e)

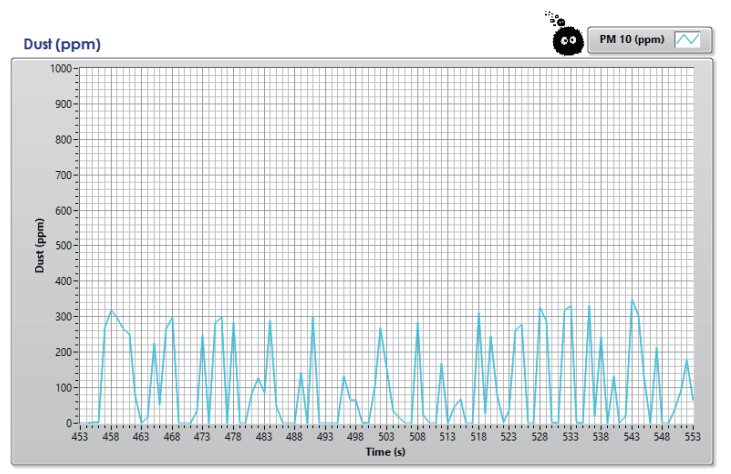

(g)

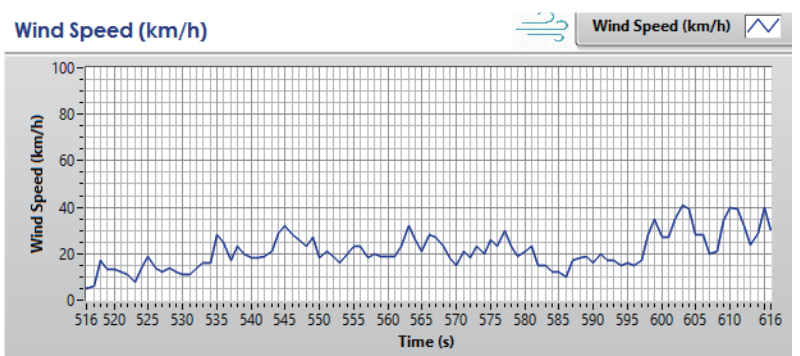

(i)

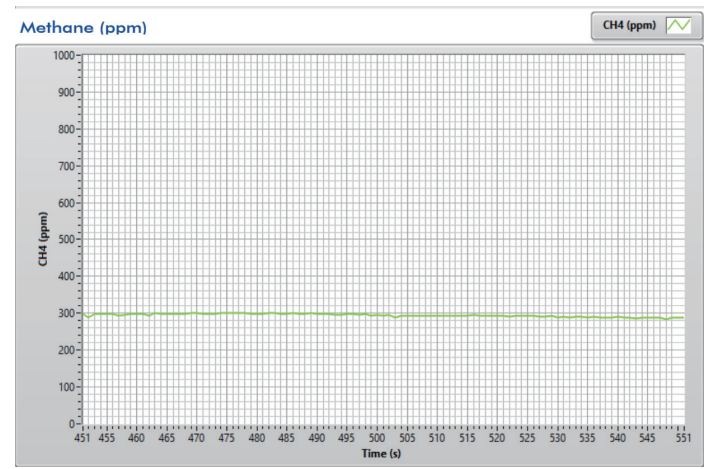

(f)

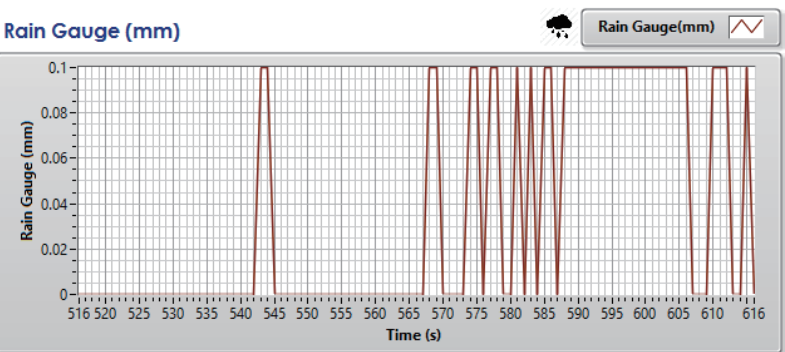

(h)

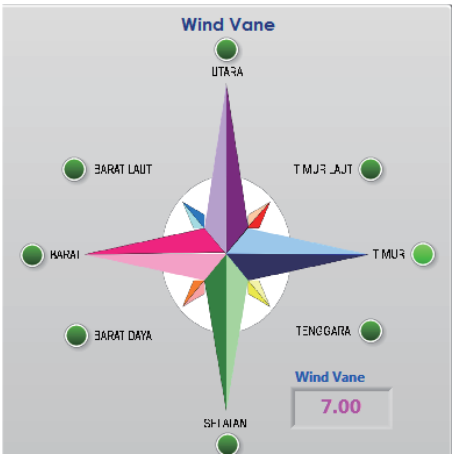

(j)

Fig. 16. (Color online) (Continued) Screen shot experimental data on fixed monitoring terminal GUI: (c) atmospheric pressure data trend, (d) carbon monoxide level data trend, (e) carbon dioxide level data graph, (f) methane level data trend, (g) dust particulate data trend, (h) rain fall data trend, (i) wind speed data trend, and (j) wind direction indicator.

either smooth or gradual changes caused by the weather condition fluctuations during the measurement period.

The collected data were also logged continuously and periodically into a database for further processing as shown in Figs. 17(b) and 18.

Figure 19 shows environmental condition data graphs. The data were plotted from a database generated during weather condition measurements as shown in Fig. 15. At the start of the measurement (10:15 a.m.), the weather was sunny, causing the ambient temperature to increase gradually from around 28 to $34{ }^{\circ} \mathrm{C}$ as shown in Fig. 19(a). The relative humidity 
gradually decreased (70 to 67\%) as shown in Fig. 19(b). The atmospheric air pressure fluctuated following the ambient relative humidity and wind speed trend data as shown in Fig. 19(c). At 11:57 a.m., the weather changed to cloudy. The ambient temperature and

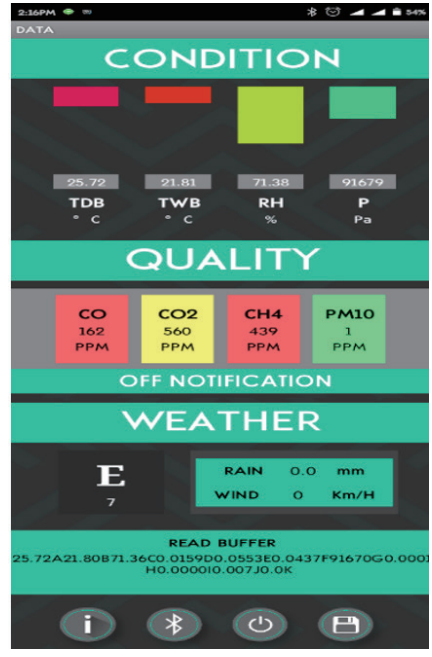

(a)

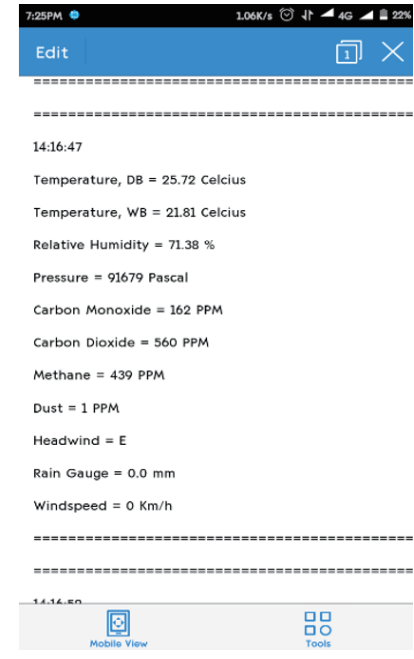

(b)

Fig. 17. (Color online) Screen shot of experimental data on mobile monitoring terminal GUI: (a) air and weather condition data, and (b) recording data.

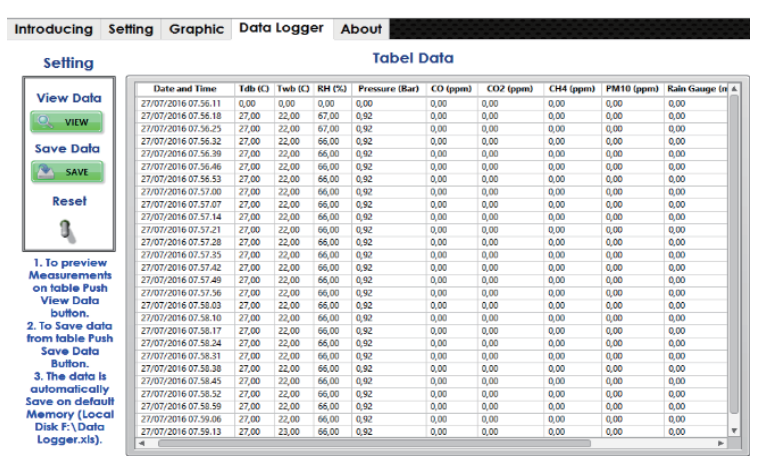

(a)

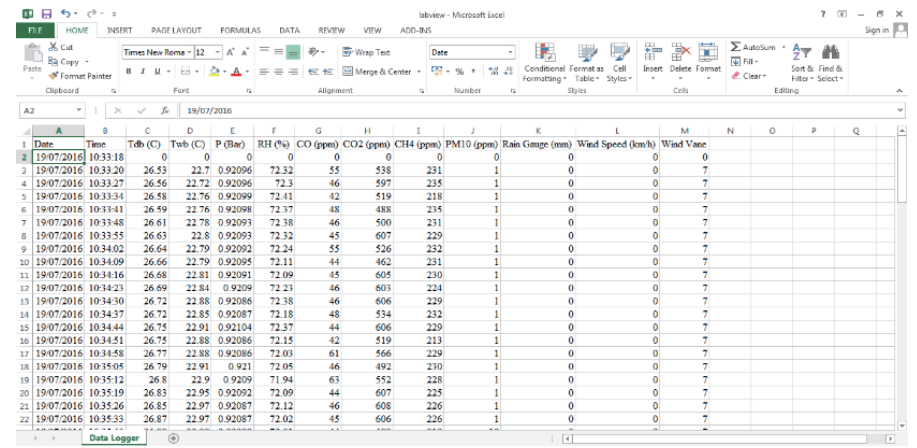

(b)

Fig. 18. (Color online) Data logger: (a) GUI format and (b) Excel ${ }^{\circledR}$ format.

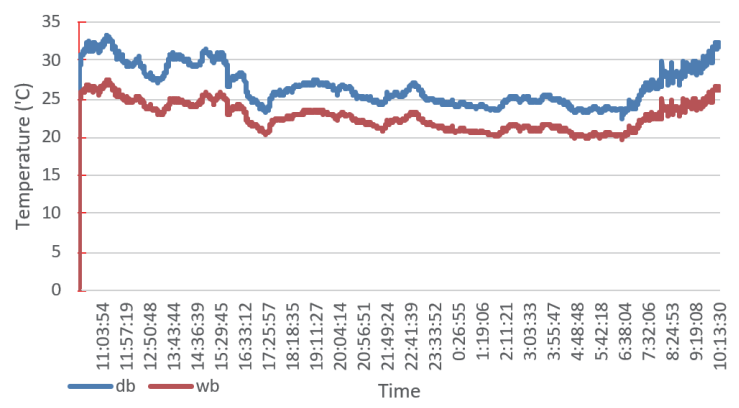

(a)

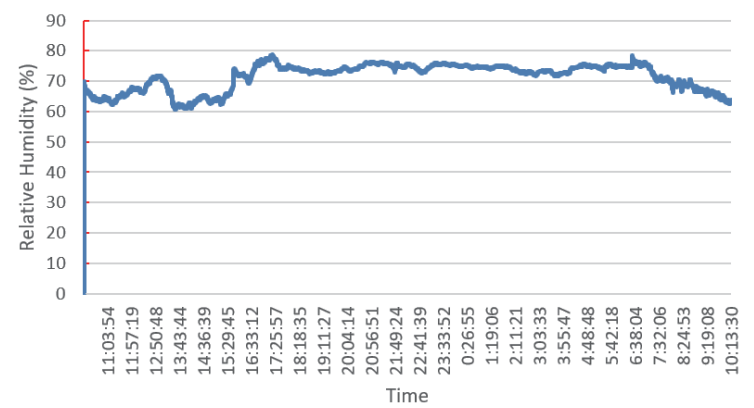

(b)

Fig. 19. (Color online) Experimental data: (a) wet and dry bulb temperature data trends and (b) humidity data trend. 


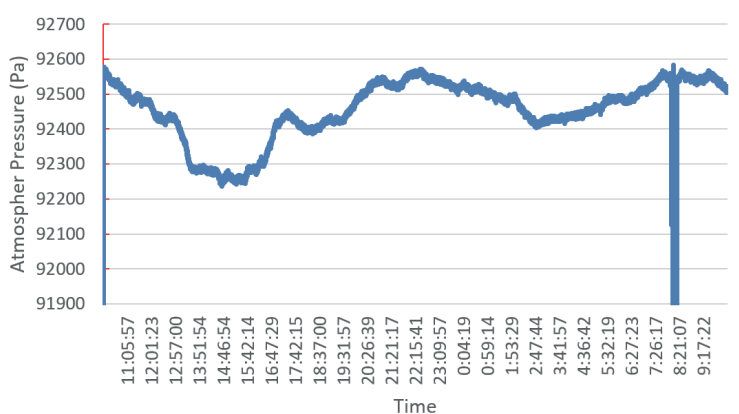

(c)

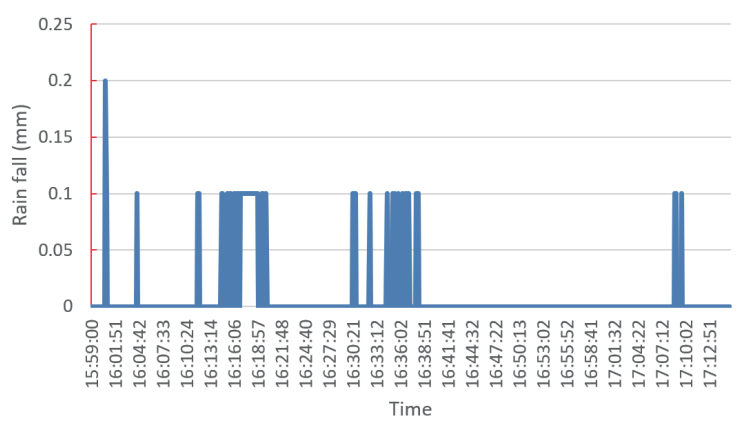

(e)

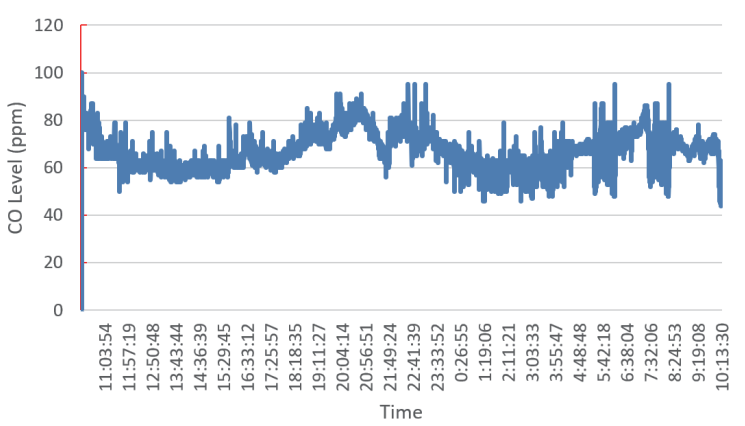

(g)

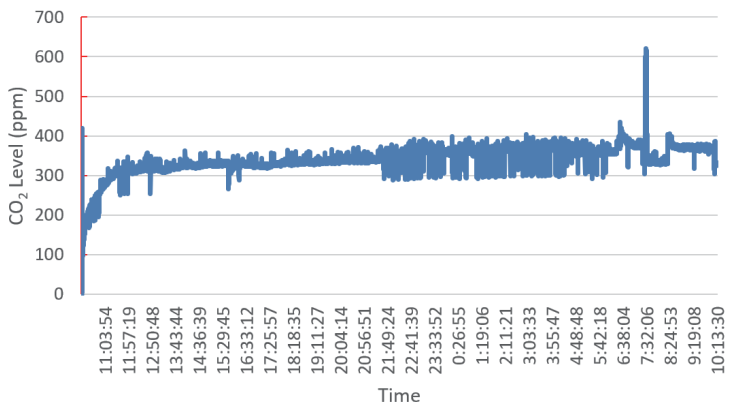

(i)

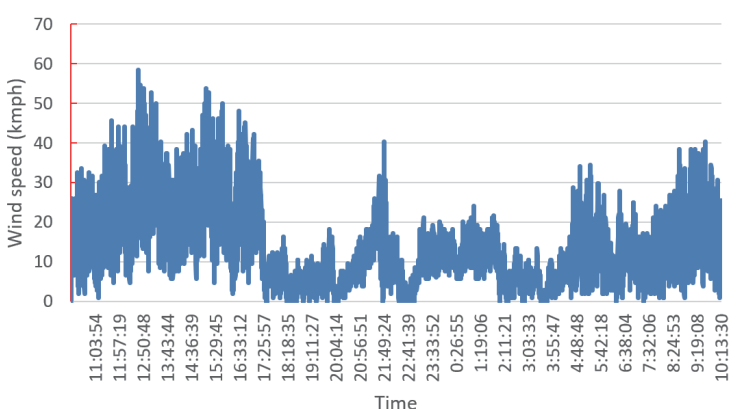

(d)

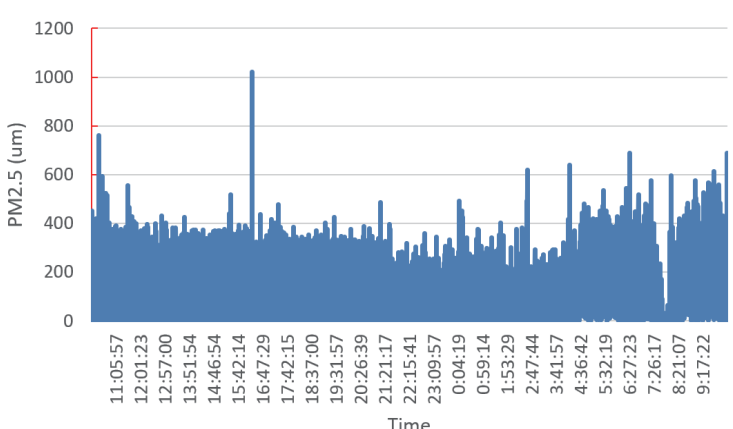

(f)

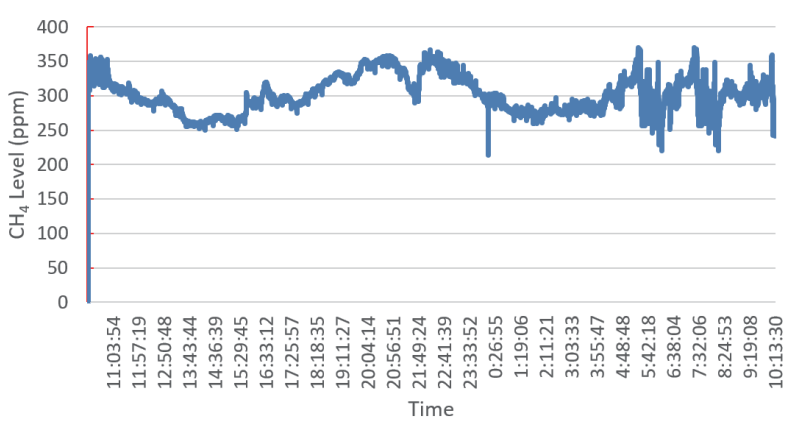

(h)

\begin{tabular}{|c|c|c|c|}
\hline Time & $\begin{array}{c}\text { Wind } \\
\text { direction }\end{array}$ & Time & $\begin{array}{c}\text { Wind } \\
\text { direction }\end{array}$ \\
\hline $10: 30: 50$ & NW & $22: 30: 05$ & NW \\
\hline $11: 30: 50$ & W & $23: 30: 02$ & NE \\
\hline $12: 30: 10$ & NW & $0: 30: 58$ & NE \\
\hline $13: 30: 39$ & NW & $1: 30: 20$ & NE \\
\hline $14: 30: 59$ & NW & $2: 30: 38$ & NE \\
\hline $15: 30: 40$ & NW & $3: 30: 17$ & SE \\
\hline $16: 30: 35$ & E & $4: 30: 39$ & SE \\
\hline $17: 30: 58$ & SE & $5: 30: 43$ & SE \\
\hline $18: 30: 52$ & E & $6: 30: 52$ & NW \\
\hline $19: 30: 35$ & S & $7: 30: 04$ & S \\
\hline $20: 30: 24$ & NE & $8: 30: 28$ & E \\
\hline $21: 30: 54$ & NE & $9: 30: 40$ & SE \\
\hline
\end{tabular}

(j)

Fig. 19. (Color online) (Continued) Experimental data: (c) atmospheric pressure data trend, (d) carbon monoxide level data trend, (e) carbon dioxide level data trend, (f) methane level data trend, (g) dust particulate data trend, (h) rain fall data trend, (i) wind speed data trend, and (j) wind direction indicator. 
air humidity trends also changed. The air quality data trends $\left(\mathrm{CO}, \mathrm{CO}_{2}, \mathrm{CH}_{4}\right.$, and $\left.\mathrm{PM}_{2.5}\right)$ fluctuated according to the air quality around the building environment as shown in Figs. 19(i), 19(g), 19(h), and 19(f), respectively. The ambient temperature continued to decrease gradually, while the relative humidity continued to increase gradually, as shown in Figs. 19(a) and 19(b). The weather then changed from drizzle to heavy rainy until 17:00 in the afternoon as shown in the rainfall and wind speed data trend in Figs. 19(e) and 19(d). It rained for around $5 \mathrm{~h}$, then the weather changed to sunny. The ambient temperature then increased gradually and the air humidity decreased gradually. The air quality conditions around the building improved because the wind speed decreased (at 17:00 to 20:00) as shown in Fig. 19(d). In the night, the ambient temperature, air humidity, and air quality conditions remained in fluctuation until the sun shines in the morning. The ambient temperature then increased gradually and the air humidity decreased gradually.

The environmental condition parameters from the experimental results are presented in Fig. 19. The proposed system can monitor the actual ambient air conditions, air quality, and weather conditions continuously and reliably in real time.

\section{Conclusions}

Experimental results show that the developed system successfully accomplished environmental condition logging and monitoring wirelessly. The proposed system can describe the environmental conditions, air quality, and weather conditions at the time of observations. With the proposed system, environmental monitoring can be performed easily, accurately, continuously, remotely, effectively, and in real time.

The proposed monitoring device has a data transmission rate delay of $2.8 \mathrm{~s}$. The sensor accuracy rates are $0.5{ }^{\circ} \mathrm{C}, 3.5 \%, 700-900 \pm 0.12 \mathrm{hPa}, \pm 50 \mathrm{ppm}, \pm 2^{\circ}, \pm 0.1 \mathrm{~m} / \mathrm{s}$, and $0.2 \mathrm{~mm} / \mathrm{tip}$ for temperature, humidity, air pressure, $\mathrm{CO}_{2}$, wind direction, wind speed, and rainfall sensors, respectively. Although the developed system has yet to be fully calibrated, in this current state, the developed system is already prepared for deployment in real-world environmental monitoring. Furthermore, all components utilized to develop the proposed system are commercial off-the-shelf (COTS) components. This system is a low-cost alternative monitoring system for large-scale wireless environmental monitoring applications.

In future research work, multiple wireless communication platform modules such as WiFi, Zigbee, and GPRS/3G/4G/LTE can be applied in the developed system to support flexible wireless connectivity.

\section{Acknowledgments}

These experimental activities were supported by the Air Conditioning and Energy Department of National Chin-Yi University of Technology (NCUT), Taiwan, and the Ministry of Science and Technology of Taiwan (MOST 107-3113-E-008-003). 


\section{References}

1 A. Kumar, I. P. Singh, and S. K. Sud: Proc Int. MultiConf. Engineers and Computer Scientists Vol. II (IMECS, 2009).

2 M. A. A. Mashud, S. M. Hossain, M. N. Islam, M. S. Islam, and M. Shahinuzzaman: Int. J. Comput. Appl. 2[2] (2012) 16.

3 N. M. Singh and K. C. Sarma: Int. J. Electron. Comput. Sci. Eng. (IJECSE). 1 (2011) 1588.

4 G. S. Nhivekar and R. R. Mudholker: E-J. Sci. Technol. (e-JST) 3 (2011) 55.

5 K. A. Noordin, C. C. Onn, and M. F. Ismail: CMU J. 5 (2006) 33.

6 B. Ivanov, O. Zhelondz, L. Borodulkin, and H. Ruser: 2002 KONNEX Scientific Conf. (2002) 1.

7 W. C. Whitman, W. M. Johnson, and J. Tomczyk: Refrigeration \& Air Conditioning Technology (Delmar Thomson Learning, 2000).

8 H. B. Glasgow, J. M. Burkholder, R. E. Reed, A. J. Lewitus, and J. E. Kleinman: J. Exp. Mar. Bio. Ecology 300 (2004) 409.

9 F. Sánchez-Rosario, D. Sánchez-Rodríguez, J. B. Alonso-Hernández, C. M. Travieso-González, I. Alonso-González, C. Ley-Bosch, C. Ramírez-Casañas, and M. A. Quintana-Suárez: 2015 Int. Wireless Communications and Mobile Computing Conf. (IWCMC) (2015) 702. https://doi.org/10.1109/ IWCMC.2015.7289169

10 W. Y. Yi, K. S. Leung, and Y. Leung: Sens. 18 (2018) 7. https://doi.org/10.3390/s18010007

11 A. Cavaliere, F. Carotenuto, F. Di Gennaro, B. Gioli, G. Gualtieri, F. Martelli, A. Matese, P. Toscano, C. Vagnol, and A. Zaldei: Sens. 18 (2018) 2843. https://doi.org/10.3390/s18092843

12 Z. Xin, D. Bo, F. Lei, and L. Wen-zhou: 2010 Int. Conf. Computer Application and System Modeling (ICCASM, 2010) 225 .

13 F. Sh. Tahir, A. M. Salman, J. K. Mohammed, and W. K. Ahmed: J. Eng. 18 (2012) 1229.

14 K. K. Khedo, R. Perseedoss, and Avinash: Int. J. Wireless Mobile Networks (IJWMN) 2 (2010) 31.

15 R. V. Prasad Y, M. S. Baig, R. K. Mishra, P. Rajalakshmi, U. B. Desai, and S. N. Merchant: ICTACT J. Commun. Technol. 2 (2011) 370.

16 S. U. Suryawanshi, D. I. Dhang, A. A. Chougule, and S. B. Mote: IOSR J. Electron. Commun. Eng. (IOSR-JMCE) (2009) 27.

17 C. B. D. Kuncoro, M. A. Falahuddin, C. A. Jaelani, and A. Muhammad: Appl. Mech. Mater. 771 (2015) 33.

18 N. I. C. Home-page: http://www.ni.com (accessed 20 January 2019).

19 T. Jen-Hao, C. Shun-Yu, L. Jin-Chang, and R. Lee: 2000 Int. Conf. Power System Technology (PowerCon 2000) 179. https://doi.org/10.1109/ICPST.2000.900052

20 Appinventor: http://www.appinventor.mit.edu (accessed 5 January 2019).

\section{About the Authors}

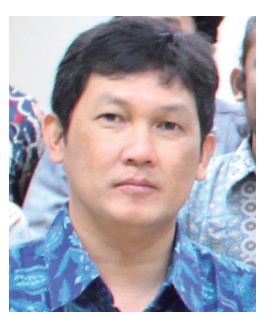

C. Bambang Dwi Kuncoro received his diploma's degree in electrical engineering-electronic engineering program from Polytechnic of Bandung Institute of Technology (ITB), Indonesia in 1993, and his bachelor's and master's degrees in electrical engineering-computer engineering program from ITB, Indonesia in 1999 and 2002, respectively. Since 1995, he is a teacher at Bandung State Polytechnic (Polban), Indonesia. Currently, he is pursuing his Ph.D. degree at the Graduate Institute of Precision Manufacturing, National Chin-Yi University of Technology (NCUT), Taiwan. His research interests include sensor integration, embedded system, control and monitoring application, wireless sensor network, wireless power transmission, and renewable energy. 


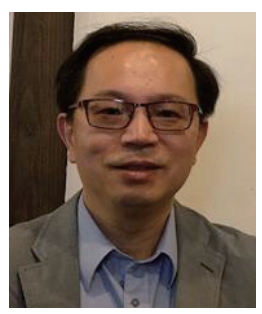

Win-Jet Luo received his master's degree in Engineering in 1994 and his Ph.D. degree in Engineering in 2000 from National Chen Kung University (NCKU), Taiwan. After he received his Ph.D. degree, Prof. Luo had been teaching in the program of Refrigeration, Air-conditioning and Energy Engineering and in the program of Electrical Engineering. Then, he was promoted to the professor position in 2008. Currently, he is a professor in the Graduate Institute of Precision Manufacturing at NCUT. His research has mainly focused on the computational fluid dynamics, micro-electromechanical systems, ventilation, energy saving, fuel cells, and microsensors. He has published several research papers in prestigious international journals, and as a result of these outstanding research, he has been invited to serve as a reviewer for journals.

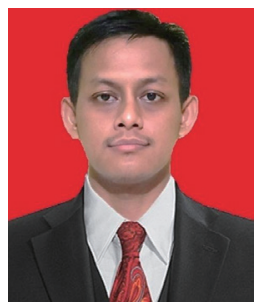

M. Rezki Selamet received his diploma's degree from the Department of Refrigeration \& Air Conditioning Engineering, Bandung State Polytechnic (Polban), Indonesia in 2016. From 2016 to 2018, he was a foreman production at PT. Astra Otoparts, Indonesia. Since 2018, he has been working at PT. Ingersoll Rand, Indonesia as an engineering staff.

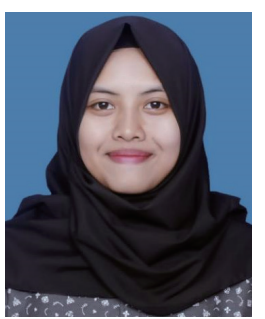

Sri Mulyati N received her diploma's degree from the Department of Refrigeration \& Air Conditioning Engineering, Bandung State Polytechnic (Polban), Indonesia in 2016. From 2016 to 2018, she was a design and estimation engineer at PT. Kinden, Indonesia. Since 2018, she has been working at PT. Daikin Airconditioning, Indonesia as a project sales engineer for commercial AC, especially for VRV System.

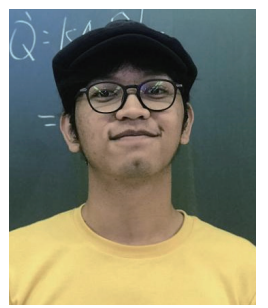

Kurniawan Andi S received his diploma's degree from the Department of Refrigeration \& Air Conditioning Engineering, Bandung State Polytechnic (Polban), Indonesia in 2016. From 2016 to 2017, he was an estimator for cleanroom design at PT. Central Filter Gunatama. From 2017 to 2018, he was a production staff at PT. Denso, Indonesia (Car Air Conditioning Dept.). Since 2018, he has been studying at NCUT, Taiwan.

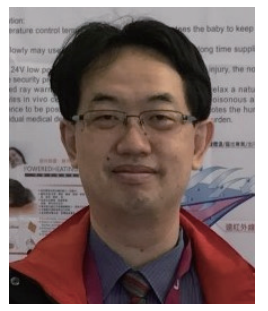

Yean-Der Kuan is the distinguished professor and former chairman (2013/02-2019/01) of the Department of Refrigeration, Air-Conditioning and Energy Engineering at the NCUT, Taichung, Taiwan. He received his Ph.D. degree from the Department of Mechanical and Aerospace Engineering at the University of Missouri, USA in 2000. Currently, Prof. Kuan is also the Director of the Taiwan Society of Heating, Refrigeration and AirConditioning, the Director of the Taiwan Energy Association, the Director of the Taiwan Association for Hydrogen Energy and Fuel Cell, and a member of 
the American Society of Heating, Refrigerating, and Air-Conditioning. His research interests include the fields of engineering saving and renewable energies, and air-conditioning components and systems. 